\title{
Degree of Availability and Practice of Level 5 Leadership by the Principals of Palestinian Private High Schools Based on Jim Collins Concepts
}

\author{
Majida Ahmad Aljaloudi ${ }^{1} \&$ Ahmad Battah $^{2}$ \\ ${ }^{1}$ Almustaqbal School, Ramallah, Palestine \\ 2 The University of Jordan, Amman, Jordan \\ Correspondence: Majida Ahmad Aljaloudi, Almustaqbal School, Palestine. E-mail: majida_15_5@yahoo.com
}

Received: Oct. 23, 2018 Accepted: Nov. 5, $2018 \quad$ Online Published: December 21, 208

doi:10.5539/mas.v13n1p172 URL: https://doi.org/10.5539/mas.v13n1p172

\begin{abstract}
This study aimed to explore the reality of leadership in Palestinian private high schools, as well as to explore the degree to which principals of these schools practice the required leadership style to move institutions from good to great, based on Jim Collins concepts. In order to achieve the objectives of the study, the theoretical literature and previous relevant studies were reviewed. A questionnaire was developed to collect the study data about the leadership reality in Palestinian private high schools, from the point of view of teachers and principals themselves. The study instrument consisted of (78) items, divided into seven domains: Leadership qualities, recruitment properties, organizational characteristics, vision, organizational culture, technological culture and building the driving force of work. After verifying the validity and reliability of the questionnaire, It has been applied to the study sample that amounted to (644) of both principals and teachers of Palestinian private high schools, whom they were selected using the stratified random sample.

The findings showed that the degree of availability of leadership qualities among principals of private high schools in Palestine was moderate, for all of its domains and items. The study revealed the existence of statistical significance differences attributed to the variables of gender, job title, years of experience and scientific qualification. The study recommended to prepare training programs for school principals according to the fifth level of leadership, and to conduct analytical and realistic studies of the internal and external environments of Palestinian private schools.
\end{abstract}

Keywords: level 5 leadership, Jim Collins concepts, private high schools

\section{Introduction}

The political, economic, cultural and social integration of any society depends mainly on education which is one of the fundamentals for the revival of this society. Education is one of the most important pillars of the intellectual, cultural and scientific development and the base of the formation of an integrated society through which the conscious individual's life is regulated at all aspects and trends.

With the acceleration of changes and challenges in the world within political, cultural, social and educational fields, generally in business organizations and particularly in educational institutions, it became necessary to have distinguished management and leadership for these organizations. They should be capable to keep abreast of innovation, believe in the importance of their career and role in setting and achieving goals and to make appropriate decisions at all levels. This will lead to achieve the effectiveness of the organization; make it able to cope with changes and adapt them, and to ensure the growth and sustainability of these institutions (Kandil, 2010).

In the educational institutions, the leadership received great and special attention in light of these changes and challenges, because of the importance of its role in reforming education, which is the cornerstone of reforming the society and its progress and achieving its objectives. The interest of all stakeholders among researchers, decision makers and education policy makers, became focused on empowerment the leadership of educational institutions in order to be able to develop visions, missions, targets and future goals (Duane, 2013).

It has become necessary and important for the management and educational leadership to be aware of the pressures of continuous and rapid change, and to have the administrative specifications and skills that enable them to carry 
out administrative tasks effectively. It has also become necessary, to invest all the available material, human and technological resources to achieve the desired goals and to achieve the best educational results with the least time, effort and financial resources (Hassan and Al-ajmi, 2013).

Alashqar (2003) stated that the school administrative function in the current era has changed and developed side by side with the rapid and successive developments. This has led the school administration to assume great responsibilities so that generations can achieve an integrated education intellectually, psychologically and socially, not only to achieve cognitive competence or transfer of culture, but also to connect the school with the society. It must also be aware of the great developments and changes taking place in the world, so that schools can play an optimal role in this change for the development of society and individuals.

Because of the importance of the educational leadership in general and the school administration in particular, researchers and scholars researched and studied them, in addition to the modern theories that have been formulated and sought to define and clarify their types and importance. Since the school is an executive educational institution, the theories, studies, policies and educational plans may become reality and practice, especially in the field of educational administration.

Since its inception, the educational administration has benefited from the theories, principles and concepts of psychology, sociology, economics, business and others in various fields of education and its application. One of these concepts is what Jim Collins included within his book "From Good to Great," published in 2001. In this book he answered the question "Why some companies make the leap ... and others do not" to find that there are seven conceptual frameworks shared by companies that have managed to turn from good to great.

Then he talked later about the possibility of applying these concepts upon schools, where the seven factors that Collins set for the transformation from good to great in corporations, can be applied to social sector organizations such as schools, and become the wheel to transfer good schools to great. Boyd (2002) agreed with Collins that the operation of schools as business leads to the existence of common denominators between the worlds of education and companies. But the main difference observed by Collins is that in companies, greatness can be defined because it is linked to the financial analysis of companies and their cumulative stock returns, while in the social sector it is difficult to identify a definition for greatness (Collins, 2005).

The most important component of the seven conceptual frameworks of Collins' concepts to transform from good to great is the so-called "level 5 leadership". These leaders have a set of qualities that distinguish them from other leaders, such as personal humility, professional will, devoting ambition to the enterprise and strong determination to do what needs to be done. The leader here is a state of duplication: humble and stubborn, timid and bridges, has the ability to be persuasive, to win the political process, and to use common interests to make decisions that will make changes (Collins, 2001).

This style of leadership is the one that must be absolute in the social sector organizations, which will later move these organizations to greatness. The school principal is an educational leader that enhances the success of all students by facilitating the supervision, development and implementation of an educational vision that will be shared and supported by the school community (Collins, 2005).

Therefore, any change initiative to transfer a school from good to great, it is important that the principal embodies the qualities of the fifth level, in addition to the qualities of all other levels of leadership. The effective leader, who stimulates commitment and strive in the light of a clear and convincing vision and promotion of high standards of performance, the competent director, who manages people and resources effectively and efficiently to pursue predefined goals. The leader of the contributing team is who contributes with individual abilities to reach the group's goals, working effectively with others within the group. The high-powered leader makes productive contributions through knowledge, skills and good work habits. Leaders of these four levels can achieve high degrees of success but not enough to elevate the school from good to excellence and sustainable greatness (Collins, 2005).

For principals, this means that they must ensure that the right people are in school, teaching and working in the right jobs. When hiring new teachers, leaders must follow the practical discipline and do not hire unqualified candidate teacher. If there is a doubt that he is inappropriate, you should continue to search until you find the right person and the highly qualified teacher. If you accept a good teacher, you may lose the opportunity to hire a great teacher. When hiring a staff member, the contract years required for the job should be made as an extended interview, not as a hypothetical period. If the teacher does not prove during that time that he is an exceptional teacher, he must be dispensed and replaced (Collins, 2005).

Whitaker (2002) agrees with Collins that the best people should be placed in the organization's greatest 
opportunities, not in the biggest problems, so that the education is upgraded and its output is good. Care must be given to who will leave the bus and who will stay there. This requires identifying the right people, putting them in the right place and excluding the inappropriate and unqualified ones. Then identify a clear vision and mission, including the development of appropriate strategy and the design of the objectives that fit them.

At the Palestinian level, schools have suffered in general and are still, from weak education and its outputs, because of many obstacles and challenges. These obstacles and challenges imposed on both schools and educational system a limited development to the rank of its peers, at the regional and global levels. Examples of such obstacles and challenges are the political and security conditions and the associated policies aimed at obstructing the Palestinian educational process, weak and limited available resources especially financial ones. Another one is the lack of availability of common vision of the school, human resources and qualified cadres capable of change and development, the use of modern technical means and sources of information, and the lack of educational decisionmaking within the school.

In spite of these obstacles and challenges, there were continuous attempts to improve the quality and level of education sector, such as improving the inputs of the educational process in terms of buildings and equipment, preparation of teachers and the level of their qualifications and skills. In the same regard, there were several attempts to develop the Palestinian curricula and to issue guides for teachers. Also, schools have been provided with good laboratories and libraries, attention to extracurricular activities is being made available according to available resources. It is hoped that this study will contribute to the achievement of the desired level of quality education, and the existence of schools with regional or global competitive outcomes.

Hence, the idea of this study emerged; the preparation and empowerment of schools leadership, whom they will be able to transform the Palestinian private high schools from good to great. This action will be based on the findings of Collins' concepts and principles, survey of the theoretical literature, the relevant previous studies, and through the point of view of principals and teachers of these schools. This may contribute to the development of the leadership of these schools, through the clarification of best practices and the identification of common general principles, which can be applied within the Palestinian private high schools.

\subsection{Research Problem and Questions}

The developed countries and societies in all aspects of their political, economic and social life have taken great attention to the educational institutions, which have become the main gateway to prosperity, progress and advancement. They took great care with quality of education in all educational stages, especially school ones, educational policy-making, preparation of teachers and curricula, technology, internal and external environment, values and ethics system, and the preparation of educational leaders ... to achieve its objectives.

The preparation and empowerment of educational leaders in schools contribute to enhance and develop their abilities to lead and manage these schools in accordance with a clear vision and high goals. In order to achieve this, the researcher sought to benefit from Jim Collins' concepts, after studying the reality of the Palestinian private high schools, to have an educational administrative level 5 leadership in these schools. This leadership is expected to contribute to the development of schools administration and the transformation of these schools from being good to being great.

This study sought to reveal the reality of the education quality in Palestinian private high schools from the point of view of the leadership, management and teachers of these schools, in order to enhance the transformation of these schools from good to great based on Jim Collins' concepts.

The problem of the study identified through the following questions:

1. What is the Degree of availability of leadership qualities of Palestinian private high schools principals, from the principals and teachers point of view, based on Jim Collins 'concepts?

2. does the degree of availability of leadership qualities of Palestinian private high schools principals, differ according to the variables: gender, years of experience, scientific qualifications and job title?

\subsection{Significance of the Study}

This research study was conducted to better understand the reality of Palestinian private high schools, based on the characteristics of Jim Collins "'Good to Great" principles. Based on this understanding, it is expected to: provide field information and data about the reality of Palestinian private high schools; benefit from the results to empower level 5 leaders, to increase the efficiency of their schools and to transform them from good schools to great schools. Within the same context, educational policy makers, development programs for private and public schools and other researchers will benefit from the results of this research. This study will open the horizon for 
further studies about the "good to great" Jim Collins theory in the local, regional and international educational system.

\subsection{Definition of Terms}

The study includes a set of terms, which are defined as follows:

Private high schools: Any licensed non-governmental civil or foreign educational institution established, headed, administered or funded by an individual, individuals, Palestinian or foreign associations, that qualify students for admission to institutions of higher education, society and the labor market (Ministry of Education and Higher Education, 2017)

Jim Collins' concepts: is a set of assumptions developed by Jim Collins to explain the transformation of some companies from "good to great" based on scientific and research views, which tried to explain the facts and to identify the reasons for this transformation. It was limited by seven factors: Level 5 leadership, First who... then what?, confront the brutal facts, the concept of the hedgehog, simplicity in the three circles, the culture of discipline, technology accelerators, flywheel and the doom loop, all together lead to construction for sustainability.

Level 5 Leadership: Is at the top of the hierarchy of leadership levels where leaders of this level are characterized by a combination of personal humility, professional will and determination, and are ambitious for the success of their institutions and have strong motivation to achieve sustainable results to move their institutions to greatness.

\subsection{Limitations of the Study}

This study was limited to the principals of private high schools in Palestine within the time frame of the academic year 2017/2018.

\section{Literature Review}

The concern in studying, categorizing, analyzing, defining, and explaining the leadership has long been started. This emphasizes its significance roll in all political, economic, educational and other institutions. It has become one of the most important pillars on which the various activities and events of organizations and institutions, both public and private, are based. It has also become an important factor in working together with individuals to mobilize energies, mobilize and create capacity, coordinate efforts, organize and properly orient actions towards achieving the goals and objectives envisaged (Abde, 2007).

Leadership is one of the most important elements of the political, economic and social structure of countries around the world. It is reliable in achieving the goals, the development and prosperity of societies. Therefore, leadership can be considered as the most creative work that is concerned with achievement and performance of objectives of the institutions and their members. (Al-ttayeb \& Al-beshti, 2004).

The theme of leadership has been at the forefront of the study subjects of management scientists and their concerns, as it has become the standard upon which any organization management succeeds. It has occupied a large and prominent part in most books of public administration, business administration, administrative psychology, educational administration and others. Leadership is also considered as one of the most important manifestations of human social interaction. It is based on the idea, that the leader is a person who has an impact on others, and works to satisfy their needs and desires, and to achieve the desired Objectives (Kanaan, 2002).

The school leadership is one of the most important factors for the success of the school, and for achieving the desired goals. One of the most important of these goals is the interest of students and their changing needs. It is incumbent upon them to make efforts to elevate the students' intellectual level and to achieve mental and general health for them, and to provide them with a safe supportive educational environment (Al-Shanifi, 2017).

Collins' management leadership concept has taken on a greater dimension than the ability to influence others and direct them toward organizational goals, planning, organizing, monitoring, and follow-up, but rather the ability to bring about change and move organizations from their current status to better future situations.

Collins' concept is considered as a proposed model that was developed to explain the transformation of some companies from "good to great" based on scientific and research views. It tried to explain the facts, and find out the reasons for this transformation. Specific and clear criteria have been adopted for the selection of companies that have reached a great position. One is the good performance of the company since a regular and specific period, which leads to a certain turning point; then the company moves to the great performance. The great performance has been defined as the total cumulative return of the value of the shares for about three times of the general market index, starting from the turning point, and over the next fifteen years. Another criterion is that the transformation from good to great has been achieved because of the company itself, not as a result of natural progress and recovery of the field of work of this company. Also that the company has been in operation and work for at least 25 years, 
its shares are traded in the business market publicly, the returns of its shares have been documented fifteen years before the publication of the research, and it is still achieving performance, continuing and rising results.

Collins' concept of good to great is based on seven basic concepts and elements, which has been used as a framework in this research:

Level 5 Leadership: For any change initiative to move a school from good to great, it is important that the chief administrator embodies the qualities of the level 5 leadership, and has special characteristics like calmness, restraint, and dedication to make everything better. Those leaders do not attribute success to themselves when their companies or organization success, and they value others and their contributions. They even attribute failure to themselves and accept blame if things do not go well. They are a paradoxical mix of personal humility and professional will, with showing an insisting on the success of the institution they belong to, more than their own success. Because of that, they are processing company for success when they leave, so that their successors continue to grow the company.

The concept of "first who ... then what". Collins found in his research that the leaders of the "good to great" companies focus first on ensuring that the right people are in the right positions in the organization. This concept is based on three beliefs. The first is to start with the right people before vision and strategy, allowing the company to adjust to the future changes. The second belief is that, if the right people are in the organization, the concerns about how to motivate and manage them do not exist; these people are self-motivated to achieve high standards. The third belief is that without the right people, the Organization will not achieve greatness, no matter what the vision is (Collins, 2001).

The concept of hedgehog, simplicity in the three circles, which means setting strategies and goals based on the recognition and knowledge of one big thing and adhere to it. The transformation from good to great requires a deep understanding and realization of three intersecting circles. Understanding what the organization can be the best in the world, and at the same time recognizing what cannot be the best in, is the first of these circles. It intersects with the circle of work towards what you feel and work passionately, and the circle of perception and knowledge of what leads the economic engine of the organization to achieve the desired returns frequently and continuously. Strict adherence to the concept of hedgehog is a culture of discipline for individuals who are integrated into disciplined thinking and carry out disciplined and consistent implementation, combined with freedom and responsibility within the framework of the system and the organization (Collins, 2001).

Technology accelerators have a profound impact on the improvements, sustainability, performance, innovation and creativity of the organizations. This was a result of increasing operational process or efficiency of management process, organization strategies or quality of marketing products. Collins found that companies that have shifted from good to great have used technology as a key accelerator of momentum, not as a producer of it (Collins, 2001).

Confronting the brutal and disappointing facts first (but not losing faith): Great leaders maintain unwavering belief that the institution can achieve its goals, regardless of the difficulties it faces. At the same time they have discipline to face these harsh truths of the current reality of their institution. The great leaders do not deceive themselves and do not try to soften problems.

Culture of discipline - the culture of freedom combined with self-discipline: Collins believes that it is a culture based on the responsibility and freedom to do any new idea; controlled by the culture of self-discipline, and knowledge of the general objectives governing the actions of workers and their decisions. There is no need for excessive controls; because disciplined people with disciplined thinking and work ethics lead to great performance and production.

Building the driving force, flywheel and the doom loop: The process of transformation from good to great is similar to the process of pushing a giant flywheel, one-way turn and role after role to grow and accumulate knowledge and experience, which increases the investment of efforts continuously. Every turn by the flywheel is build on the work done in advance, that is, each batch is a small part of the cumulative effect on the flywheel. The transformations in the great institutions did not occur as a result of one event or a great program or a stroke of luck or chance, not even a sudden revolution; it resulted through a cumulative process and successive events step by step, decision after decision until getting great sustainable results.

\subsection{Previous Studies}

Al-Mana'imah Study (2005) aimed to identify the role of school administration in public and private schools in improving the educational process in the Gaza governorates, and to reveal the prevailing administrative patterns in these schools. The researcher used the analytical descriptive method, and the study sample was randomly 
selected and consisted of (400) teachers from (40) public and private schools belonging to the education departments in the cities of Gaza and Khan Younis. The researcher prepared a questionnaire consisting of (60) paragraphs divided into five domains. The most prominent result was that most of the principals of public and private schools follow the democratic pattern of the school administration. The study recommended the need to develop laws for private schools to ensure the protection of teachers, and equality in rights and privileges similar to those of public schools.

Al-ajarma (2012) conducted a study aimed at identifying the prevailing leadership styles of private school principals, and its relation to the quality of education from teachers' point of view in Amman Governorate. The researcher used the descriptive associative research methodology, where a random sample of 500 teachers was selected, and he developed a questionnaire to measure leadership styles, and another to measure the quality of education. The most important finding of the study was that the degree of practicing leadership styles by private school principals in Amman governorate was moderate with an average of 3.31 and a standard deviation of 0.79. One of the most important recommendations made by the researcher was to provide a training program to improve the leadership practice by principals, to empower them and to improve the quality of education in private schools as well.

The Kasapri study (2015) aimed to develop the criteria for selecting educational leaders in private schools in Palestine, in light of the reality and the dimensions of personal quality. The study sample consisted of (470) teachers and administrators of Alfrair and Tarasanta Schools in Palestine during the first semester of the academic year 2014/2015. The researcher constructed a questionnaire consisting of three parts. One of the most important results of the study is that the degree of practice of selecting educational leaders in reality is high, according to the established criteria. Based on the results of the study, the researcher developed 67 criteria for selecting educational leaders in Palestinian private schools, in light of the reality and the personal quality dimensions. The study recommended the adoption and application of these standards within the selection process of educational leaders of private schools in Palestine.

A study was conducted by Gray (2005), aimed at exploring the "very successful" characteristics and behaviors of school principals as measured by the performance of students. The study was based on the qualitative research model described by Collins' "From Good to Great" and his research about the success of private sector leadership. The population and sample of the study consisted of six "very successful" principals and five "comparative" principals selected from schools in San Diego, Orange and Riverside. The research questions were answered through semi-structured interviews with the participating school principals. The results indicated that all principals showed all the characteristics and behaviors of Level 5 leadership, according to Collins.

The LaChance study (2007) aimed to determine whether schools rated as excellent through Blue Ribbon Schools program, are equivalent with the characteristics of companies that have moved from good to great? The researcher tried to define Jim Collins model as a theoretical framework for educational principals, to achieve excellence in education, through using a survey as a tool for assessment of greatness. The study showed statistically significant results at leadership level, recruitment practices, strong hedgehog concept, and technology accelerator characteristics.

The Lamper study (2007) aimed at applying Jim Collins research model, and finding the relevance of its results with purposed sample of 10 schools in the UK. The study followed the multi-case approach, and the opinions of school leaders were explored through semi-structured interviews. The responses were coded according to the key concepts of Collins research along with additional classifications that emerged through interviews. One of the most important results of the study, that the results of the research "good to great" is related to the results of the cases studied. The study recommended conducting further research and studies to verify this relationship.

Dominy study (2009) aimed to examine similarities and to compare the qualities of leadership of high-performing school principals at the Georgia Intermediate School, with the qualities of Level 5 leadership by Collins. The researcher used the multiple case study methodology, and she monitored three principals within their school environments, interviewed and reviewed the documents and profiles of these principals. The data was analyzed depending on Collins' description for the fifth level of leadership. The results showed that the three principals have the leadership qualities of the fifth level leaders. One of the most important recommendations of this study was the need for school systems to train current and potential leaders on the basis of the level 5 leadership.

The McCoy study (2010) aimed at disclosing the educational leadership behaviors of three primary school principals (study sample) whose schools were classified at Level 5 of excellence in 2008. Qualitative research methodology was used to collect and analyze data through in-depth and structured interviews with principals and teachers, to discover the educational behavior of leadership. The study discovered the leadership behaviors that 
would help all students achieve efficiency and move from good to great based on Collins' theory. It recommended the application of educational leadership behaviors for principals in schools that have similar factors of low social and economic conditions.

The Zanglin study (2011) aimed to examine the human resources application of Collins concepts when recruiting good teachers in private schools, whom they helped to support students' achievement and excellence in a city in the south of United States. The researcher used an inductive reasoning methodology and collected data through reviewing documents and interviewing HR officials and school principals. The main findings of the study were: private schools principals showed more leadership abilities at level 5, private schools can easily provide Collins' theoretical standards significantly and it can provide the development of faculty to be leaders within the organization. The researcher hopes that this study will contribute to providing school principals with Collins' approach for recruitment of good teachers.

Sharratt study (2016) aimed to explore the leadership skills needed to transfer an educational system from good to great and then to innovation. It also aimed to provide a contemporary research guide on improving the school and the system with focusing on leadership innovation. The study was conducted on a sample of 40 schools in the United States, Australia, Chile and Canada. The researcher used the method of observation and reviewing the documents and detailed data of the work of school leaders. The study found that the leaders of education and innovation have the vision, mission, and goals of the school that achieve students' aspirations. They have a coherent and internal education system, staff development, curriculum improvement, understanding of staff needs for change, development of strong community contacts, continuing of feedback about school progress. The study recommended the need for transition to innovation for both educational leadership and school.

Goode study (2017) aimed to identify the reality of three principals who were able to maintain the success of their schools and their success as educational leaders in Victoria, Australia. This study followed a preliminary one made by the researcher five years ago. The researcher focused, in particular on their attitudes towards change and how this affects their leadership practices. The researcher used a multi-perspective case study methodology. The data was collected through individual or group interviews with all school groups, reviewing school documents, viewing principals and many school assignments. The study found that principals' qualities, their work and practices had a role in creating, developing and improving internal conditions, managing expected and unexpected internal tensions, and facing challenges from the external environment effectively. The researcher recommended further research about the role of teachers in the success of these schools.

\subsection{Commentary on Previous Studies}

The development and improvement of educational leadership in general and the school in particular, has been a major and important factor in many studies and research, because it is one of the main pillars for improving education, its results and outputs. Therefore, this study is based on previous studies that examined the educational and school administration, mainly high schools, Collins concepts and the studies that proposed models in many aspects of education. Through reviewing and exploring previous studies relevant to the current study, and identifying their theoretical literature and scientific methodology, it was possible to conclude that the current study meets with a series of studies about the leadership of high schools. Examples are the study of Alajarmi (2012), and the study of Kasapri (2015), which addressed private schools and the role of the principal in the development of education and school. It also meets with Lamper study (2017), Gray (2005) and others through the objective or methodology or application of Collins' concepts. It also benefited from previous studies in the preparation of the theoretical framework, and the development of the study instrument. The current study is unique to previous Arab studies by constructing its methodology based on Collins' concepts and principles. It is also unique with the study population, which is represented by the principals and teachers of private high schools in Palestine, and in relying on Collins' thoughts to transform Palestinian private high schools from good to great.

\section{Methodology and Procedures}

\subsection{Methodology of Study}

The researcher adopted the descriptive developmental survey through collecting data and constructing the instrument which was distributed to the study sample, and using statistical analysis to answer the study questions.

\subsection{Population and Sample of the Study}

The study population consisted of all (110) principals of the Palestinian private high schools in the West Bank, in addition to the teachers of these schools with a total number of (3397) teachers according to Ministry of Education statistics for the school year 2016/2017. The study sample was selected using the stratified random method, it consisted of all (110) principals of private high schools, in addition to (534) teachers of these schools, to have a 
total study sample of (644) principals and teachers. Table 1 shows the characteristics of the study sample based on descriptive statistics.

Table 1. Demographic characteristic of the study sample

\begin{tabular}{lllll}
\hline Category & Groups & $\mathrm{N}$ & $\%$ & Total \\
\hline \multirow{2}{*}{ Gender } & Male & 243 & 37.7 & 644 \\
& Female & 401 & 62.3 & \\
\multirow{2}{*}{ Years of } & 5 y and less & 149 & 23.1 & \multirow{2}{*}{644} \\
& 6-less than10 y & 194 & 30.1 & \\
\multirow{2}{*}{ Academic Qualifications } & 10 y and more & 301 & 46.8 & \\
& B.A & 429 & 66.6 & \multirow{2}{*}{644} \\
\hline \multirow{2}{*}{ Job title } & M.A & 213 & 33.1 & \\
& Ph.D. & 2 & 00.3 & \\
\hline
\end{tabular}

\subsection{Study Instrument}

After reviewing the theoretical literature and previous studies related to Collins concepts and others, the researcher designed a questionnaire with 5-point Likert scale. It consisted of (78) items distributed over (7) domains. The domains were: leadership characteristics, recruitment properties, organizational characteristics organizational culture, vision, technological culture and driving force of work.

\subsection{Validity and Reliability of Study Instrument}

The instrument was presented in its initial form to (10) of the educational arbitrators to judge its validity. The reliability of the study instrument was tested through using the alpha-cronbach coefficient to test the internal consistency of the items of all domains and the study instrument as a whole. This was done by distributing the questionnaire to an exploratory random sample of (30) of the principals and teachers. The results ranged between 85.4 as minimum, and 97.0 as maximum, which means an accepted result for the study. Table 2 shows the results of alpha-cronbach coefficient values.

Table 2. Alpha-cronbach coefficient

\begin{tabular}{lll}
\hline \multicolumn{1}{c}{ Domain } & No. of Items & Alpha-cronbach \\
\hline Leadership characteristics & 17 & 97.0 \\
Recruitment properties & 9 & 88.2 \\
Organizational characteristics & 11 & 85.4 \\
Vision & 11 & 95.3 \\
Organizational culture & 12 & 87.2 \\
Technological culture & 8 & 86.8 \\
Driving force of work & 10 & 95.5 \\
Study instrument & 78 & 97.6 \\
\hline
\end{tabular}

\subsection{Statistical Analysis Methods}

The data were collected using the study instrument, then encoded and analyzed using the statistical package for the social sciences (SPSS). Likert scale of 5-point was used for all measures. Means and standard deviations of the responses of the study sample were calculated. They were used to analyze the availability and degree of leadership qualities for each of the seven domains, each item of every domain and for the total domains as well. This statistical analysis was made according to the following variables: gender, years of experience, academic qualification and job title. T-test was used to calculate the differences between the responses of the study sample individuals of the domains; according to gender and job title Variables (each variable has two groups). One-way analysis of variance (ANOVA) was used for years of experience and academic qualifications variables (each variable has three groups).

\section{Results and Discussion}

\subsection{Results and Discussion Related to Question 1}


What is the Degree of availability of leadership qualities of Palestinian private high schools principals, from the principals and teachers point of view, based on Jim Collins 'concepts?

In order to answer this question, means and standard deviations have been calculated for all domains and for the study instrument as a whole. Table 3 shows the results of this analysis.

Table 3. Degree of availability of leadership qualities

\begin{tabular}{lllll}
\hline Rank & Domain & Mean & S. Deviation & Degree \\
\hline 1 & Organizational culture & 3.01 & 0.89 & Moderate \\
2 & Technological culture & 2.98 & 0.98 & Moderate \\
3 & Recruitment properties & 2.83 & 0.96 & Moderate \\
4 & Driving force for work & 2.76 & 1.12 & Moderate \\
5 & Leadership characteristics & 2.74 & 1.08 & Moderate \\
5 & Organizational characteristics & 2.74 & 0.86 & Moderate \\
7 & Vision & 2.73 & 0.93 & Moderate \\
- & Leadership qualities & 2.82 & 0.92 & Moderate \\
\hline
\end{tabular}

The results of the analysis indicated that the degree of availability of leadership qualities of Palestinian private high schools principals was moderate, for all domains of the study and for the study instrument as a whole. The means ranged between 2.73 and 3.01 .

The degree of availability of leadership qualities among private school principals at an average level indicates that it is classified within the third level of leadership, based on Jim Collins concepts. This means that those principals are administrators who manage the work, direct the employees toward the goals, and work in a bureaucratic environment that strictly applies the regulations. This is because of the circumstances and possibilities available to them, within the educational policies in the general Palestinian education system. This finding may also indicate that school principals have often not received special qualification in running these schools. Some of them took over the position as a result of seniority, social relations or special interests.

\subsection{Results and discussion related to question 2}

Does the degree of availability of leadership qualities of Palestinian private high schools principals, differ according to the variables: gender, years of experience, academic qualifications and job title?

In order to answer this question, means and standard deviations of responses of the participants toward the leadership qualities in accordance with the four variables have been calculated, to check if there are differences between these means. Table 4 shows the results of this analysis.

Table 4. Means and standard deviations of responses of the participants toward the leadership qualities in accordance with gender, job title, years of experience and academic qualifications

\begin{tabular}{llll}
\hline Variable & Group & Mean & S. Deviation \\
\hline \multirow{2}{*}{ Gender } & Male & 2.67 & 0.85 \\
& Female & 2.91 & 0.96 \\
Job title & Principal & 4.22 & 0.42 \\
& Teacher & 2.35 & 0.71 \\
Years of experience & 5 years and less & 2.63 & 0.78 \\
& 6-less than10 years & 2.56 & 0.73 \\
& 10 years and more & 3.07 & 1.03 \\
Academic qualifications & B.A & 2.64 & 1.08 \\
& M.A & 3.18 & 0.00 \\
& Ph.D. & 1.87 & 0.92 \\
\hline
\end{tabular}

Based on the results of table (4), it seems that there are differences between the means responses of the participants in accordance with the variables of gender, job title, years of experience and academic qualifications. To explore if these differences have statistical significance or not, two tests of statistical analysis were conducted. The first was t-test for both variables of gender and job title, and the second was one-way analysis of variance (ANOVA) for both variables of years of experience and academic qualifications.

The results of t-test analysis for gender and job title are presented in table (5). 
Table 5. T-test of means differences for gender and job title toward leadership qualities

\begin{tabular}{llll}
\hline Variable & T value & Degree of freedom & Significance \\
\hline Gender & 3.20 & 558 & $0.00^{*}$ \\
Job title & 32.06 & 243 & $0.00^{*}$ \\
\hline
\end{tabular}

(*): Statistically significant at level of $(\alpha \leq 0.05)$

The results of this analysis show that there are statistically significant differences between the means of responses of the participants, which can be attributed to the variables of gender and job title. From table (4), we can see that these differences were in favor of "females" and principals groups, because they have the highest means. By this we can conclude that the degree of availability of leadership qualities of Palestinian private high schools principals, differ due to the variables of gender and job title. Females agree more than males with the questionnaire items. This may be due to the nature of the females whom they accepts reality and cohabits with it, or because that the higher proportion of the sample was females. Principals agree more than teachers with the questionnaire items. This is may be due to the fact that principals want to show themselves excellently, and that they perform their duties perfectly.

The second statistical analysis done was one-way analysis of variance (ANOVA), to explore the statistical significant of mean differences according to both variables of years of experience and academic qualifications. The results were summarized in table (6).

Table 6. One-way analysis of variance (ANOVA) for years of experience and academic qualifications toward leadership qualities

\begin{tabular}{lllll}
\hline Variable & Sum of squares & Mean of squares & F value & Sig. \\
\hline Years of experience & 24.242 & 12.121 & 15.865 & $0.00^{*}$ \\
Academic qualifications & 29.854 & 14.927 & 19.537 & $0.00^{*}$ \\
\hline
\end{tabular}

$(*)$ : Statistically significant at level of $(\alpha \leq 0.05)$

The results of this analysis show that there are statistically significant differences between the means of responses of the participants, which can be attributed to the variables of years of experience and academic qualifications. From table (4), we can see that these differences were in favor of " 10 years and more of experience" and "master degree qualification", because they have the highest means. By this we can conclude that the degree of availability of leadership qualities of Palestinian private high schools principals, differ due to the variables of years of experience and academic qualifications. Both groups of "10 years and more of experience" and "master's degree holders" showed higher approval than other groups. This is because that most of these two groups are principals, whom they are trying to show good leadership.

5. Recommendations: In light of the results of the study, the researcher recommends the following:

- To prepare an advanced leadership university programs to qualify, train and empower principals.

- To provide schools with systems and programs those reinforce the foundations of level 5 leadership for current and potential leaders.

- To provide schools with guidelines of best practices and procedure manuals for selection and recruitment of the staff.

- To conduct analytical and realistic studies about the internal and external environments of private schools, and to uncover the problems and obstacles experienced by the Palestinian school education sector.

- To adopt the findings that the study has concluded, by the Palestinian private schools, and to be tested and adapted in accordance with the special needs of the private high schools in Palestine.

- To conduct further studies and research for applying the findings within public schools as well.

\section{Acknowledgement}

I would like to thank my family: My husband and my children for supporting me spiritually throughout writing this research. 


\section{References}

Al-ashkar, Y. (2003). The role of high school administration in community development (Unpublished master thesis). Islamic University, Gaza.

Al-shneifi, A. (2017). The role of school leaders in providing a safe learning environment for high school students in the city of Al- Riyad. Journal of the Islamic University for Educational and Psychological Studies, 26(2), 327-348. https://doi.org/10.12816/0049181

Collins, J. (2017). From good to great: Why some companies make the leap and others don't. Al-Kuwait: Jarir Bookstore.

Collins, J. (2001). Good to great: Why some companies make the leap and others don't. New York: Harper Business.

Collins, J. (2005). Level 5 leadership: The triumph of humility and fierce resolve. Harvard Business Review, $83(7 / 8), 136-146$.

Dominy, S. (2009). Leadership Characteristics of Georgia High Performance Middle School Principals Compared to Collins' Level 5 Leaders. Electronic Theses \& Dissertations. p. 284.

Dwany, K. (2013). Educational leadership. Amman: Dar Al Masirah for publishing and distribution.

Goode, M. (2017). A study of successful principal leadership: Moving from success to Sustainability, doctoral dissertation, Melbourne Graduate School of Education, the University of Melbourne, Australia.

Gray, S (2005). Good to Great: A qualitative Study of School Principals Who Made the Leap, doctoral dissertation, San Diego State University, USA.

Hassan, H., \& Alajami, M. (2013). Educational administration (3 ${ }^{\text {rd }}$ ed.). Amman: Dar Al Masira for publishing and distribution.

Kandil, A. (2010). Administrative leadership and management of innovation. Amman: Dar Alfikr.

Kilani, A. \& Dirani, M. (1998). Modeling in educational planning between theory and practice. Journal of King Saud University, Educational Sciences and Islamic Studies, 10(1), 65-88.

LaChance, L. (2007). Moving Schools from Good to Great: A study of Excellence in Education, doctoral dissertation, Capella University, USA.

Lamper, D. (2007). Good to great schools: The relevance of a business model to a school context, doctoral dissertation, Centre for Educational Studies, the University of Hull, UK.

McCoy, V. (2011). Amultiple Case Study of Principals' Instructional Leadership in "LEVEL 5" Schools of Excellence for Improvement, doctoral dissertation, University of Arkansas, USA.

Omar, A. (2008). Dictionary of contemporary Arabic language ( $3^{\text {rd }}$ ed.). Cairo: world of books.

Sharratt, L. (2016). Moving from Good to Great to Innovation Leadership, a paper presented at the International Congress of School Effectiveness and Improvement.

Whitaker, T. (2002). Dealing with Difficult Teachers ( $2^{\text {nd }}$ ed.). Larchmont, NY: Eye on Education. https://doi.org/10.4324/9781315855264

Williams-Boyd, P. (2002). Educational Leadership: reference handbook. Sant Barbra, CA: ABC-CLIO, Inc.

Zanglin, A. (2011). Comparing Good to Great Hiring Practices in Private and Public Schools. Doctoral dissertation, Walden University, USA.

\section{Copyrights}

Copyright for this article is retained by the author(s), with first publication rights granted to the journal.

This is an open-access article distributed under the terms and conditions of the Creative Commons Attribution license (http://creativecommons.org/licenses/by/4.0/). 